\title{
Analysis and modeling of variables of the precise shredder's pneumatic material transport's system
}

\author{
Krzysztof Tyszczuk ${ }^{1 *}$, Kazimierz Peszyński ${ }^{2}$, Adam Mroziński ${ }^{2}$, Grzegorz Śmigielski ${ }^{1}$ \\ ${ }^{1}$ Kazimierz Wielki University in Bydgoszcz, Poland \\ ${ }^{2}$ University of Science and Technology in Bydgoszcz, Poland
}

\begin{abstract}
The technological process of materials shredding, especially biological material, with a precise RPW shredder, requires control of its many elements. One of them, not methodologically recognized so far, is the flow of air conditioning an appropriate product's quality and shredding capacity. In the article, there are presented the first results of studies of the process of pneumatic transport in a shredder, its analysis and simulation attempts, which shall make it possible to reach the optimum product's capacity and quality, constituting the basis for biological diet supplements.
\end{abstract}

Keywords: pneumatic transport, flow of air, Prandtl tube, precise shredder

\section{Precise shredding of oil seeds}

High temperature and oxidation accompanying the shredding process, are damaging to vitamins, enzymes, volatile substances and many other active substances occurring in seeds being the base of diet supplements. In the standard shredding method, the process temperature may reach even $100{ }^{\circ} \mathrm{C}$. In circumstances like that, all the volatile and thermosensitive active plant's ingredients are destroyed. In case of the discussed precise shredding with the RPW shredder, the increase of the material's temperature, as compared to the input, is little and it neither destructs nor lowers chemical and biological properties of active plant's ingredients. So, it makes it possible to obtain them in an intact state, in the form of powder of optimum parameters. The essence of the precise RPW shredder's operation consists in quick flow of material through the system of active and passive discs, and the degree of shredding and capacity are conditioned by the variables of the technological process and the design form of the working tool.

The basis of good performance of the oil seeds' shredding process (obtaining of the required degree of shredding) is, among the others, the selection of an appropriate flow of air of the required negative pressure and velocity, and the constant volume of feed material at the inlet to the shredder.

\footnotetext{
*Corresponding author: krzytysz@ukw.edu.pl

Reviewers: Milan Sága, Alžbeta Sapietová
} 
So, here the process of shredding is based on the operating needs defined as to the value and quality, among the others:

1. for the type of material - arrangement and type of working discs in the shredder,

2. for the type of material and degree of shredding - rotational velocity of the shredder's knife (within the scope of $1420-3600 \mathrm{~min}^{-1}$ ),

3. to maintain the capacity (efficiency of the process) - the volume of the negative pressure in the tank for the shredding product and on the material's inlet to the shredder - suction apparatus setting (pneumatic transport),

4. for high process's efficiency (no blocking by batch) - the volume of the material fed to the charging hopper - set by controlling of the motor of the feeding screw's storage bin.

The above presented operations and their state, must be controlled in the course of the process and have to be verified on a current basis (closed control system). Activities like these are based on the mechatronic control systems of the selected process' stages, are verified via computer-aided decisive processes, including the supported AI ones $[1,2,3,4$, $5,6,7]$.

\subsection{Construction of a test stand}

A test stands (Fig. 1) consists of the following, main working sub-systems: material storage bin with outlet's adjustment, a precise shredder RPW-11TN, $\mathrm{Z}_{1}$ - tank for shredded material, with monitoring $-\mathrm{a}$ camera via the door viewer, $\mathrm{E}_{4}$ - cyclone, $\mathrm{E}_{3}$ - suction apparatus.

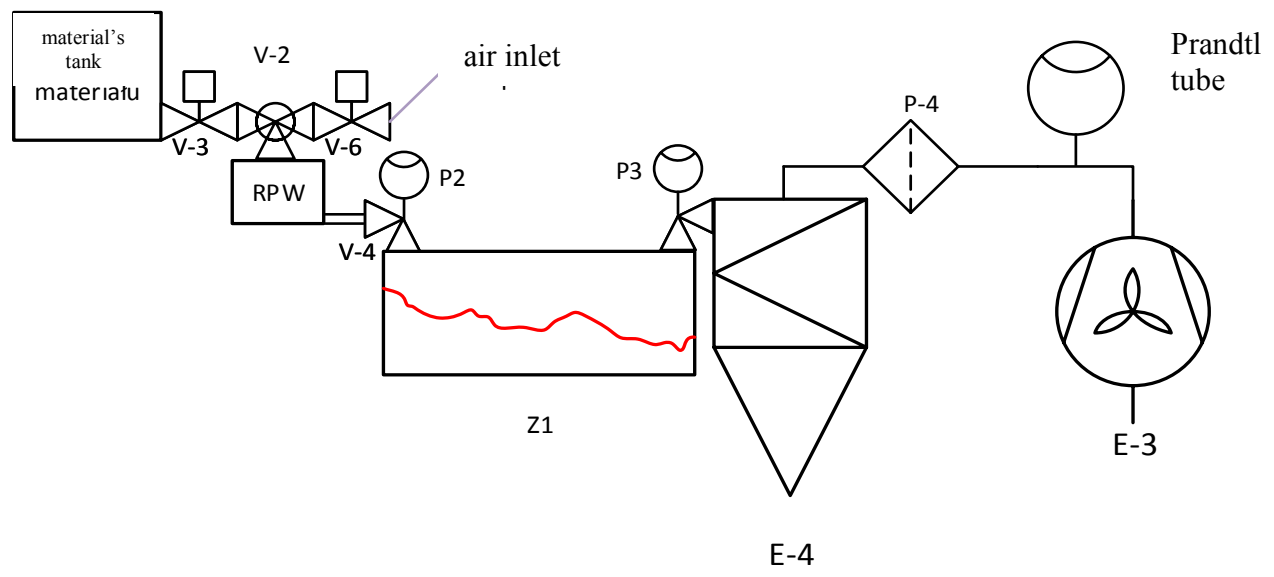

Fig. 1. A block scheme of a test stand of a precise shredder RPW with the pneumatic transport measurement

Material is shredded by thin knives shields and remains in the shredding area for only 23 seconds and then leaves the shredder not increasing its temperature. In this case, the pneumatic transport shall be the necessary procedural condition. It comes down to the flow of air forced by the $\mathrm{E}_{3}$ suction apparatus, and then to the flow of the mixture air-product, conditioning an appropriate process's efficiency and the shredding degree. In case of excessive velocity of the flow of air, there may occur the loss of the smallest reduct fractions (shredded material), what shall be visible in the control cyclone. In order to recognize the pneumatic transport's phenomenon, in the stand there have been applied the control elements - a flow meter, vacuum meters and a Prandtl tube, all with digital measurement converters. A computer application making it possible to control the actuators 
and to visualise the process variables, has been developed in the LabVIEW environment [7] - view of the control panel presented in Fig. 2.

The conducted tests aim at determining of the allowable (for a given material) negative pressure and the velocity of flow.

\subsection{The pneumatic transport's arrangement in the shredder}

Establishment of the model shredding process with identification of the subsystem of the material and reduct's pneumatic transport on the experimental way, what occurs in case of the described activity, is based on identification of the conducted measurements [8]. On the basis of the experiment, there took place determination of the characteristic parameters' values, and the earlier analysis and knowledge of the inlet-outlet relationship in the process of precise shredding of seeds of high fat content was a considerable problem's simplification. By the analysis of the signal and the process, one comes to the model of the system, what constitutes the basis for the process' steering $[8,9]$, what means the project of interfering in the process that means determining of the adjustment values for the purposes of possibly easy reaching of the required process's functionality, in particular at constant design shredder's parameters being the test facility (Fig. 3) [10, 11, 12, 13, 14, 15, 16].

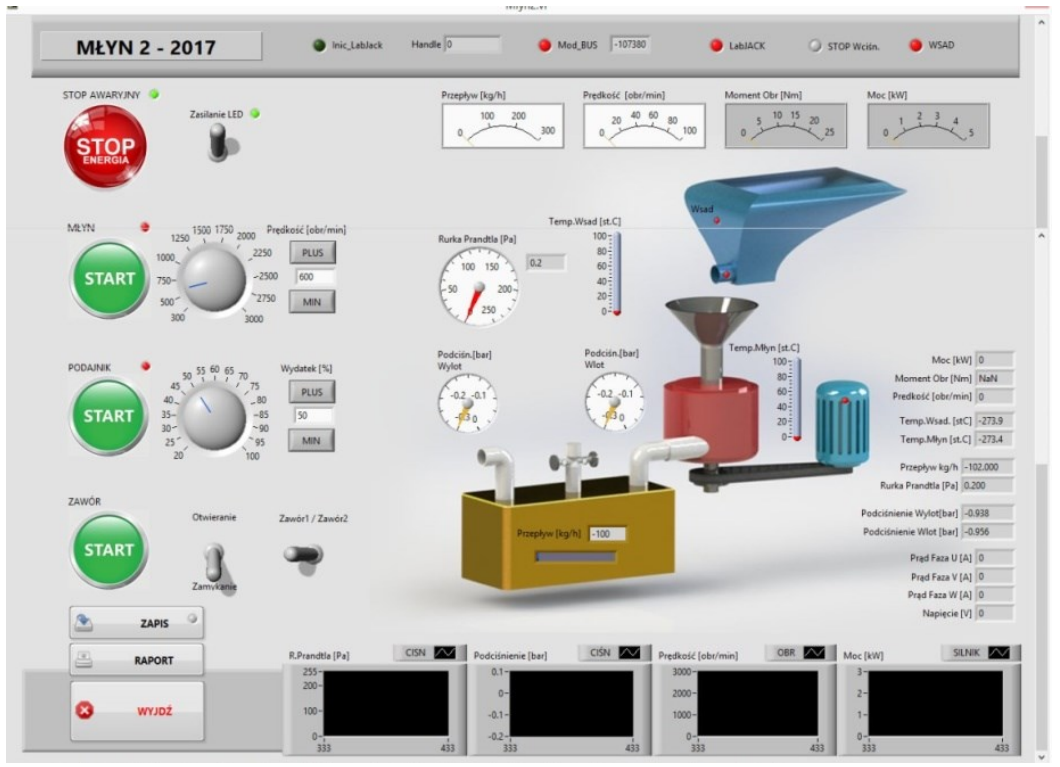

Fig. 2. View of the screen of the control desk of the precise RPW shredder's test stand with measurement of the selected pneumatic transport's parameters 


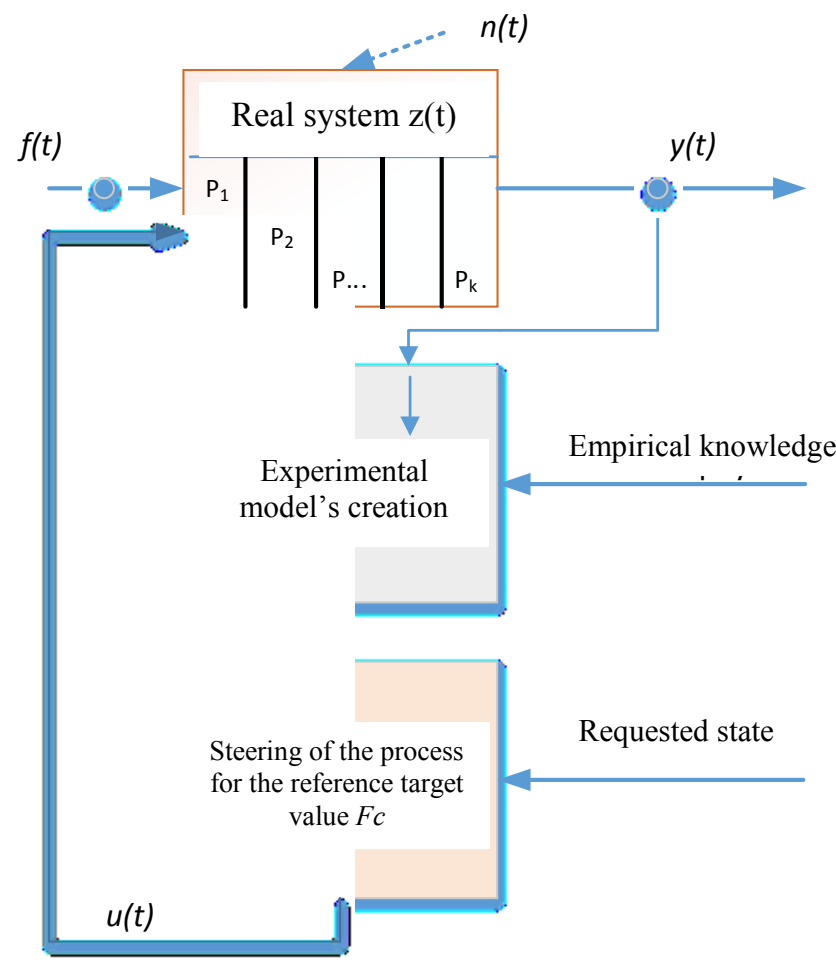

Fig. 3. The principle of the shredding process's control is based on its experimental model, $f(t)-$ input vector (including the process and design factors), $z(t)$ - the system's state vector depending on the state of subsystems $\mathrm{P}_{1}-\mathrm{P}_{\mathrm{k}}, u(t)$ - control vector, $n(t)$ - disturbances vector

\section{Measurements of the pneumatic transport parameters}

\subsection{Introduction to parameters}

The preliminary measurements used to determine the pneumatic (flow) shredder's properties, have been conducted with the use of the atmospheric air flow. The authors are aware of the fact, that the mixture of air and shredded seed flowing in the real system, shall have slightly different flow properties. However, the preliminary tests may already give many valuable hints making it possible to improve the system's design and its final modelling. In Fig. 4 there is presented the schematic diagram of the shredding system, referring to the arrangement presented in Fig. 1.

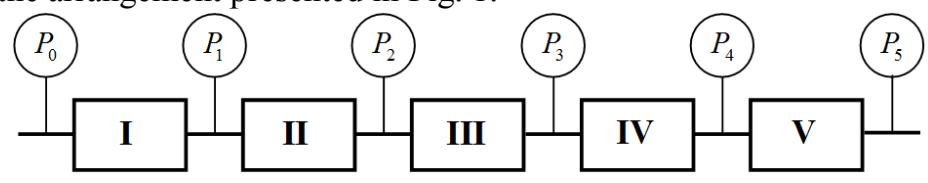

Fig. 4. The schematic diagram of the elements of the shredder's arrangement assumed at the time of experimental tests

Pursuant to the Fig. 4, the whole system has been divided into sections according to the direction of the air flow. In such a system, the suction apparatus $E_{4}$, which is the element generating the flow, is in the section $\mathbf{V}$. The tests have been commenced from determining 
of its flow properties. The velocity of the flow of air in the pipeline exhausting air from the cyclone, was measured with the Prandtl tube, $\varnothing 6 \mathrm{~mm}$, the pipeline has the internal diameter of $d_{p}=45 \cdot 10^{-3} \mathrm{~m}$. The pneumatic resistances of devices preceding the suction apparatus on the air flow way (mixer, shredder, tank, cyclone) were simulated by assembly of a throttle diaphragm on the inlet pipeline (Fig. 5).

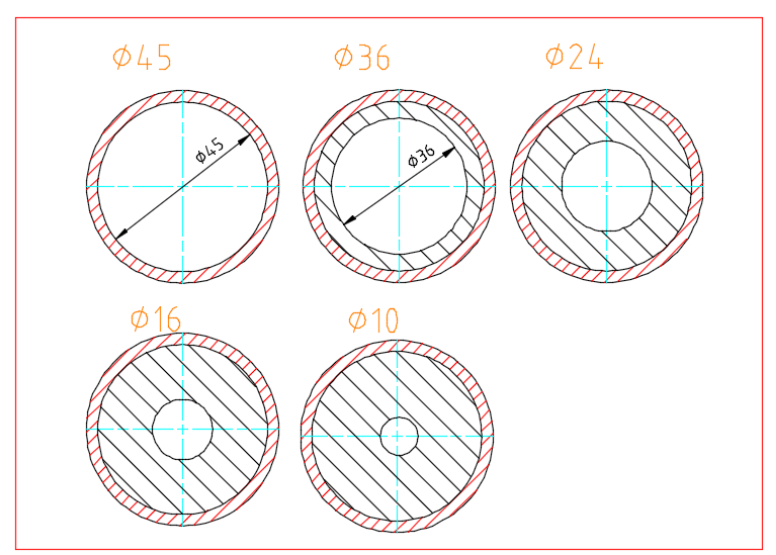

Fig. 5. Set of control holes for the for the measurement of the flow of air on the test stand of the RPW shredder

These diaphragms constitute local resistance deciding on the intensity of air flow through the examined system. The kinematic pressure $P_{\mathrm{k}}$ measured with the use of the Prandtl tube, is the measure of the flow velocity in the tube's section axis (maximum velocity $v_{\mathrm{C}}$ ), according to the formula

$$
v_{\mathrm{C}}=\sqrt{\frac{2 P_{\mathrm{k}}}{\rho_{\mathrm{air}}}}
$$

where: $\rho_{\text {air }}$ is the density of the flowing air.

It has been initially assumed, that at the time of operation of the shredding system, the flow is turbulent. For the turbulent flow, the velocity distribution curve cannot be determined analytically.

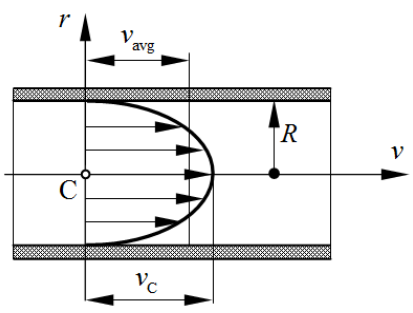

Fig. 6. Flow in the pipeline of a column section: a) laminar, b) turbulent

Due to that, the semi-empirical relations are used. The Prandtl power formula is one of the best-known dependencies describing the velocity distribution

$$
v=v_{\mathrm{C}}\left(1-\frac{r}{R}\right)^{\frac{1}{n}}
$$


where: $v, v_{c}, r, R$ are the values presented in Fig. 6 , while $1 / n=1 / 6 \div 1 / 10$ is the exponent for the range of Reynolds numbers $R e=4 \cdot 10^{3} \div 3,2 \cdot 10^{6}$, these values refer to smooth pipes $[8,9]$. The equation 2 loses its importance by the same wall. The mean velocity $v_{\text {avg }}$ in the turbulent flow may be determined by averaging of the velocity distribution. From the practical point of view, it would be very advantageous to determine the mean velocity depending on the maximum velocity $v_{\mathrm{C}}$ on the section axis and the coefficient $n$, at the assumed distribution curve (assumed coefficient $n$ ).

In order to do that, one should set the intensity of flow in a given pipeline.

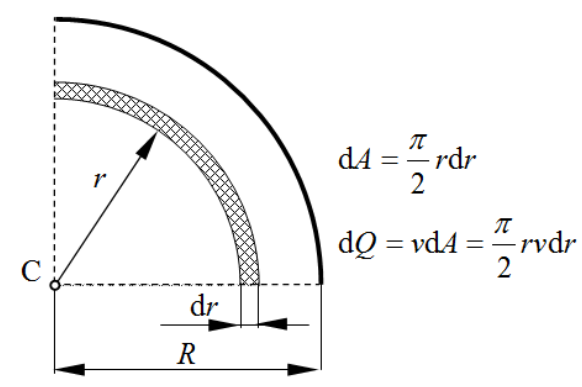

Fig. 7. Integration area in circular section

In case of assuming that the velocity distribution is determined by the power Prandtl formula and the elementary section is determined by the formula $\mathrm{d} A=0,5 \pi r \mathrm{~d} r$, the elementary intensity of flow of $1 / 4$ of elementary section is determined by the formula $\mathrm{d} Q=0,5 \pi v(r) r \mathrm{~d} r$ (Fig. 7) we may determine the mean velocity following substitution of $v=v(r)$ from the formula (2) on the basis of dependency:

$$
v_{\mathrm{avg}}=\frac{Q}{A}=\frac{4 \frac{\pi}{2} v_{\mathrm{C}} \int_{0}^{R}\left(1-\frac{r}{R}\right)^{\frac{1}{n}} r \mathrm{~d} r}{\pi R^{2}}=\frac{4 v_{\mathrm{C}} \mathrm{I}}{\pi R^{2}}
$$

where the integral $\mathrm{I}=\frac{\pi}{2} \int_{0}^{R}\left(1-\frac{r}{R}\right)^{\frac{1}{n}} r \mathrm{~d} r$ in the numerator of the formula (3) is the intensity of flow through $1 / 4$ of section, at the velocity $v_{\mathrm{C}}=1 \mathrm{~m} \cdot \mathrm{s}^{-1}$. After its multiplication by $4 v_{\mathrm{C}}$ we shall receive the flow intensity in the section. The mentioned integral causes certain analytical problems, however it may be calculated with the use of a special function $\Gamma$.

Substituting $\frac{r}{R}=t$, where $r=R t$ and $\mathrm{d} r=R \mathrm{~d} t$ we receive:

$$
\mathrm{I}=\frac{\pi}{2} \int_{0}^{R}(1-t)^{\frac{1}{n}} t R^{2} \mathrm{~d} t=\frac{\pi R^{2}}{2} \int_{0}^{R}(1-t)^{\frac{1}{n}+1-1} t^{2-1} \mathrm{~d} t=\frac{\pi R^{2}}{2} \frac{\Gamma(2) \cdot \Gamma\left(1+\frac{1}{n}\right)}{\Gamma\left(3+\frac{1}{n}\right)}
$$


Following subsequent transformations, we get:

$$
\mathrm{I}=\frac{\pi R^{2} n^{2}}{2(2 n+1)(n+1)}
$$

Due to what, the finally searched dependency $v_{\mathrm{avg}}=f\left(v_{\mathrm{c}}, n\right)$ is determined by formula

$$
v_{\text {avg }}=\frac{Q}{A}=\frac{4 v_{\mathrm{C}} \mathrm{I}}{\pi R^{2}}=\frac{2 \pi v_{\mathrm{C}} \frac{R^{2} n^{2}}{(2 n+1)(n+1)}}{\pi R^{2}}=\frac{2 n^{2}}{(2 n+1)(n+1)} v_{\mathrm{C}}
$$

For the commonly assumed, at the time of turbulent flows' analysis, the value $n=7$ was received

$$
v_{\text {avg }}=0,8167 v_{\mathrm{C}}
$$

The formula (7) was used to determine the mean velocity in the circular section and at the same time the intensity of flow during experimental tests. The basic assumption making it possible to use the formula (7) is the turbulent flow of air in the pipeline. The character of the flow in determined with the Reynolds number expressing the relations of the inertial force to the force of internal friction, following the use of the formula (7), determined with the formula

$$
R e=\frac{\rho v_{\mathrm{avg}} D}{\mu}=0.8166 \frac{\rho v_{\mathrm{C}} D}{\mu}
$$

where: $\rho$ is the mass density of the flowing air, $\mathrm{kg} \cdot \mathrm{m}^{-3} ; \mu$-dynamic viscosity of the flowing air, $\mathrm{kg} \cdot \mathrm{m}^{-1} \cdot \mathrm{s}^{-1} ; D-$ internal diameter of the pipeline, $\mathrm{m} ; v_{\mathrm{C}}$ - velocity of air on the pipeline's axis, $\mathrm{m} \cdot \mathrm{s}^{-1}$.

At the time of the examinations with the suction apparatus, the maximum velocity on the pipeline's axis $v_{\mathrm{C}}$ (measured with the Prandtl tube) was within the range $v_{\mathrm{C}}=(5.77 \div 20,52) \mathrm{m} / \mathrm{s}$. For the mean values $\rho=1.2 \mathrm{~kg} \cdot \mathrm{m}^{-3}, \mu=1.7 \cdot 10^{-5} \mathrm{~kg} \cdot \mathrm{m}^{-1} \cdot \mathrm{s}^{-1}$ and $D=45 \cdot 10^{-3} \mathrm{~m}$ there were received the values $R e \approx 15000 \div 55000$, what proves the turbulent flow of air in the suction apparatus.

\section{Conclusions}

The basic achievement of the theoretical analysis, which is the introduction to the measurements of air flow through the suction apparatus with local resistances on the pipeline supplying air is determination of the formula (7), which makes it possible to determine the mean air velocity in the pipeline leading to the suction apparatus.

In the future studies on the pneumatic properties of the shredding system, the throttle holes shall be replaced with real elements $(I \div I V$, Fig. 4), what shall make it possible to determine the pneumatic local holes of the shredding system. 


\section{References}

1. J. Flizikowski, M. Macko, J. Czerniak, A. Mroziński, Implementation of genetic algorithms into development of mechatronic multi-edge's grinder design. ASME 2011 Int. Mech. Eng. Congress and Exposition, IMECE, (2011)

2. M. Macko, J. Flizikowski, The method of the selection of comminution design for nonbrittle materials. AIChE Annual Meeting, Conference Proceedings, (2010)

3. M. Macko, J. Flizikowski, K. Tyszczuk, G Śmigielski, I. Rojek, A. Mroziński, J. Czerniak, A. Tomporowski, Mechatronic implementations used for the effective monitoring and data acquisition of the shredding process. ASME 2016 International Design Engineering Technical Conferences and Computers and Information in Engineering Conference. IDETC2016, Charlotte, North Carolina, USA. August 21-24, (2016)

4. M. Macko, J. Flizikowski, Z. Szczepański, K. Tyszczuk, G. Śmigielski, A. Mroziński, J. Czerniak, A. Tomporowski, CAD/CAE applications in mill's design and investigation. Proceedings of the 13th International Scientific Conference: Computer Aided Engineering, Lecture Notes in Mechanical Engineering, Springer International Publishing AG, 343-351 (2017)

5. J. Czerniak, D. Ewald, M. Macko, G. Śmigielski, K. Tyszczuk, Approach to the monitoring of energy consumption in eco-grinder based on ABC optimization. Communications in Computer and Information Science 521, Springer International Publishing Switzerland, 516-529 (2015)

6. P. Pecháč, M. Sága, Controlling of local search methods' parameters in memetic algorithms using the principles of simulated annealing. Proc. Eng. 136, 70-76 (2016)

7. G. Śmigielski, R. Dygdała, H. Zarzycki, D. Lewandowski, Real-time system of delivering water-capsule for firefighting. Hard and Soft Computing for Artificial Intelligence, Multimedia and Security. Advances in Intelligent Systems and Computing, 534, Springer International Publishing Switzerland, 102-111 (2017)

8. M. Sága, P. Kopas, M. Uhríčik, Modeling and experimental analysis of the aluminium alloy fatigue damage in the case of bending-torsion loading. Proc. Eng. 48, 599-606 (2012)

9. M. Sága, R. Bednár, M. Vaško, Contribution to modal and spectral interval finite element analysis. Vibration Problems ICOVP 2011, Springer Proceedings in Physics 139, 269-274 (2011)

10. J. Flizikowski, A. Mroziński, A. Tomporowski, Active monitoring as cognitive control of grinders design. AIP Conference Proceedings, 1822 020006, doi: http://dx.doi.org/10.1063/1.4977680, (2017)

11. J. Flizikowski, A. Tomporowski, M. Macko, A. Mroziński, Inżynieria rozdrabniania biomasy. Monografia pod redakcją A. Mrozińskiego. ISBN: 978-83-64423-35-2. Wydawnictwo Grafpol Agnieszka Blicharz-Krupińska, Bydgoszcz (2016)

12. J. Flizikowski, T. Topoliński, M. Opielak, A. Tomporowski, A. Mroziński, Research and analysis of operating characteristics of energetic biomass micronizer. Eksploatacja i Niezawodność/Maintenance and Reliability 17, No. 1, 19-26 (2015)

13. Y. A. Cengel, J. M. Cimbala: Fluid Mechanics. Fundamentals and Applications. McGraw-Hill, (2006)

14. K. Peszyński, D. Perczyński, E. Smyk, P. Kolber, Experimental verification of velocity distribution in different cross-sectional ventilation ducts. Proceedings of $23^{\text {rd }}$ International Conference Engineering Mechanics 2017, 770 - 783 (2017) 
15. M. Macko, Economic-energetic analysis of multi-edge comminution of polymer recyclates. Przemysł Chemiczny 92 (8), (2013)

16. J. Flizikowski, M. Macko, Method of estimation of efficiency of quasi-cutting of recycled opto-telecommunication pipes. Polimery/Polymers 46 (1), (2001) 